\title{
Radiologic and ultrasonographic studies of kidneys in goat
}

\author{
G. A. Ragab, M. M. Seif* , U. A. Hagag \\ Department of Surgery, anesthesiology and radiology, Faculty of Veterinary Medicine, Beni-Suef \\ University
}

\begin{abstract}
A study was performed on fifty normal goats for radiographic (only 20 animals), and sonographic (the all 50 animals) investigations. Radiographic results revealed that, both kidneys had bean shaped and smooth contour. The right kidney position was constant due to its relation with the liver, while, the left kidney was mobile and its position varied according to the degree of fullness of the rumen due to its long mesentery. The sonographic results revealed the position, shape, dimensions and echogenicity of kidneys, by using 3.5/5.0 MHz curved transducer and 6.0/8.0 MHz linear transducer. The renal capsule was represented by a very fine echogenic lines around the kidney that couldn't be distinguished from the peri-renal fat. The cortex was more echogenic than the medulla and had uniform finely granular hypoehoic pattern. The corticomedullary junction was slightly more echogenic than the cortex due to the presence of the arcuate arteries. The medulla was observed as hypoechoic area interrupted by bright echogenic lines representing the recesses and interlobular arteries that gave the appearance of typical medullary pyramids. The dimensions of the right kidney were $5.32 \pm 0.12,2.79 \pm 0.07,0.64 \pm 0.01,1.52 \pm 0.03,2.74 \pm 0.09,1.27 \pm 0.06,1.25 \pm 0.05$, and $1.72 \pm 0.09$; and the dimensions of the left kidney were $5.34 \pm 0.12,2.80 \pm 0.07,0.65 \pm 0.01,1.55 \pm$ $0.03,2.76 \pm 0.09,1.26 \pm 0.06,1.28 \pm 0.05$, and $1.73 \pm 0.1$, for the length, width, cortical thickness, medullary thickness, depth, diameter of renal sinus, diameter of renal parenchyma, and circumference of renal pyramids respectively.
\end{abstract}

Excretory urography is commonly indicated when abnormal renal size and shape (suspicious of renal masses, sub lumbar masses, other intrapelvic masses, renal calculi or hydronephrosis) were determined by palpation or survey radiography. Also when there is persistent haematouria and other forms of abnormal urine (Watters, 1980; Morgan and Silverman, 1982). It can be used to draw some general conclusions about renal functions, especially renal opacification, or more specially the time to maximum renal opacification. Once the contrast has been administered, can potentially predict disorders of, renal perfusion, glomerular filtration, intra-renal or extra-renal obstruction, tubular necrosis, and contrast toxicity. (Charles 2003) .Excretory Urography techniques included Low volume, rapid infusion technique with abdominal compression, Low volume, rapid infusion technique without abdominal compression, Low volume and slow infusion technique without abdominal compression and High volume prolonged or drip infusion technique with abdominal compression. (Biery, 1978; Owens, 1982).

Over the late 20 years, ultrasonographic investigation has been widely adopted for sheep and goat to determine fetal number during the mid-trimester of pregnancy. However, other diagnostic applications for ultrasonographic examination in sheep and goat practice have been largely restricted to investigate the diseases of the urinary system especially partial or complete urethral obstruction in intensively reared entire male particularly the castrated males (Scott et al., 2001).

The purpose of this study was to describe the radiographic image and ultrasonographic appearance of normal kidneys in goats.

Materials and methods

This study was performed on a total number of 50 goats of both sex, age ranged from 6 months up to 6.5 years, and of weight ranged from $10 \mathrm{~kg}$ to $50 \mathrm{~kg}$ bwt. (Table 1). The animals were injected with terramycine $20 \%$ of a dose 1 $\mathrm{ml} / 10 \mathrm{~kg} \mathrm{~b}$. wt. and ivermectine $1 \mathrm{ml} / 50 \mathrm{~kg}$. Then the animals were kept under observation for 3 weeks.

Radiographic investigation. Animal preparation was done by withholding off food for $48 \mathrm{~h}$ and water for $12 \mathrm{~h}$. For gastrointestinal tract emptying, the animals were administered three tablets/animal of active charcoal and rectal enema and in order to sedate the animal prior to exposure and to limit unnecessary movements, the animals were injected with diazepam 2 $\mathrm{mg} / \mathrm{kg}$ body weight via intramuscular injection.

* Corresponding author. Tel.: +20 012 7456156;

Fax: +20 0822327982

E-mail address: seif@,bsu.edu.eg

(Mohamed Seif) 
The technique of choice was high volume prolonged or drip infusion technique with abdominal compression. The compression device consisted of a piece of elastic bandage placed around the caudal abdomen, just caudal to the wings of the ilia and cranial to the pubis.

For the intravenous injection, the jugular vein was selected. The dose of the contrast agent (urographin) is calculated according to the weight of the animal (1200 mg iodine / $\mathrm{kg}$ body weight not exceed $35 \mathrm{gm}$ iodine). This volume was mixed with equal volume of $5 \%$ glucose solution and infusion was adjusted to be completed over a period of 10 minutes. Contrast material remaining approximately 8 minutes after beginning of infusion may be administrated within the last two minutes. Ventrodorsal and lateral radiographs were taken during infusion after 5 minutes of the start of injection of the contrast agent.

After completing infusion, the canula was withdrawn and the animal was placed in the previously determined radiographic projections. After that the compression device was applied ventro-dorsal and lateral radiographs were taken 10 minutes after application of the compression device. When renal and ureteral opacification had been determined to be acceptable, the compression device is removed and radiographs were repeated for visualization of the caudal ureter and bladder.

Ultrasonographic investigation. This part of study was conducted on 50 animals. The Used Apparatus was 240 PARUS VET Pie Medical Equipment (B.V. Philipsweg 16227 Maastricht, Netherlands). Ultrasonographic examination was carried out using 3.5/5.0 MHz curved array electronic transducer (R40-401665) and 6.0/8.0 $\mathrm{MHz}$ linear array probe (6 CM-401663). High quality Sony printing paper type I (normal 110 mm x 20 m), Sony Co. Tokyo Japan was used.

Animal preparation by reflecting the sound beam, Food and water were withheld for 12 hours. All examinations were done while the animal in standing position, the right paralumber fossa was shaved and the transducer skin contact was achieved by applying a liberal quantity of acoustic. Numerous ultrasonograms of the kidneys in transverse and longitudinal views were taken, till the entire structure of the kidney had been studied. The echogenicity of the renal cortex, medullary pyramids and renal sinus were assessed and compared

For visualization of the right kidney longitudinally, the transducer was placed behind the last rib high on the paralumber fossa. The transducer was held in a slight oblique position, because the longitudinal axis of the right kidney is inclined caudally. For visualization of the left kidney longitudinally, the transducer was placed over the middle of the paralumber fossa, parallel to the lumber vertebrae. Ultrasonographic visualization of both kidneys transversally was performed by placing the transducer at right angle to the longitudinal axis of each kidney. Sagittal planes of both kidneys were taken where the transducer was placed parallel to the animal body.

Ultrasonographic measurements included length of the kidney (the distance between the cranial and caudal poles of the kidney, measured in the longitudinal plane); depth of the kidney (the distance between the ventral and dorsal face of the kidney, measured in the transverse plane at the level of the renal hilus); width of the kidney (the distance between the lateral and medial margins of the kidney, measured in the transverse plane at the level of the renal hilus); diameter of the renal parenchyma and renal sinus (measured from dorsal to ventral in the transverse plane at the level of the renal hilus) and circumference of the 3 largest medullary pyramids.

\section{Results}

The radiographic investigation showed that, the nephrogram phase was demonstrated on the radiographs made after 5 minutes from the onset of injection of the contrast agent but it was best seen immediately after the end of infusion of the contrast materials, it is still evident till 40 minutes from the end of injection (Fig.1).

The shape, size and location of kidneys were evident. Two kidneys were found in the examined animals, left and right to the median plane. Both kidneys were bean shaped with smooth and regular margins. The medial border of both kidneys appeared straight with a depression in its center, the hilus. The hilus leads to the renal sinus that enclosed the renal pelvis that become clearly evident when filled with the contrast materials.

The position of the right kidney was constant and always cranial to the left kidney. It was demonstrated lying ventral to the caudal third of the last thoracic vertebra and the first and second lumber vertebrae. In the ventro-dorsal view it appeared lying right to the median plane $1.3 \mathrm{~cm}$ far from the vertebral column. The anterior pole was rounded and covered by the $13^{\text {th }}$ rib and extended to the $12^{\text {th }}$ intercostals space. The 
posterior pole was more convex and narrower than the anterior pole and lied under the second lumber vertebra (Fig. 2).

The position of the left kidney was variable and always caudal to the right one. On the ventro-dorsal view it was noticed ventral to the level of the right kidney and superimposed on the vertebral column, slightly left to the median plane or may be completely shifted to the right side. On lateral radiographs it was noticed below the right kidney and ventral to the $2^{\text {nd }}, 3^{\text {rd }}$ and $4^{\text {th }}$ lumber vertebrae (Fig. 1, 2).

The length of the right kidney and left kidney was $4.5-6.5 \mathrm{~cm}$. The ratio of the right kidney length and left kidney length to that of the $2^{\text {nd }}$ lumber vertebra was (2.1-2.6: 1 , average 2.3) (Table 1). On the lateral view the long axis of the kidneys was mostly horizontal. Sometimes the long axis of the left kidney was vertical

The pyelographic phase of the urogram could be demonstrated in the radiographs taken at the end of infusion of the contrast solution but it was best visualized after 10 minutes from the end of infusion post application of the compression device and remain evident till 30 minutes from the end of infusion (Fig. 2, 3).

The renal pelvis was demonstrated as a radiopaque crescent in the radiolucently appearing kidney sinus. It was narrowed toward the both poles of the kidney. On the medullary margin of the pelvis there were 10-12 pelvic recesses or diverticulae, which were indented by the renal papillae (Fig. 2, 3). Sometimes the origins of the ureters might be seen.

Ultrasonographic investigation revealed that both left and right kidneys were examined through the right flank region. In longitudinal view, both kidneys appeared bean shape with smooth contour. Three distinct anatomic regions could be recognized. These regions consisted of a bright central echo complex corresponding to the renal sinus and peri-renal fat, a hypoechoic region surrounding the pelvis representing the renal medulla and an outer zone of intermediate echogenicity, the renal cortex, (Fig. 4, 5). The average dimensions of the right and left kidneys were $5.32 \pm 0.12 \mathrm{~cm}$ and $5.34 \pm 0.12 \mathrm{~cm}$ for length and $2.79 \pm 0.07 \mathrm{~cm}$ and $2.80 \pm 0.07 \mathrm{~cm}$ for width respectively (Table 2,3 ).

The renal capsule was represented by a very fine echogenic lines around the kidney that couldn't be distinguished from the peri-renal fat. The cortex was more echogenic than the medulla and had uniform finely granular hypoehoic pattern. The average cortical thickness was 0.64 $\pm 0.01 \mathrm{~cm}$ and $0.65 \pm 0.01 \mathrm{~cm}$ for the right and left kidneys respectively (Table 2,3 ). The corticomedullary junction was slightly more echogenic than the cortex due to the presence of the arcuate arteries (Fig. 4,5 ).

The renal medulla was observed as hypoechoic area interrupted by bright echogenic lines representing the recesses and interlobular arteries that gave the appearance of typical medullary pyramids. The average medullary thickness was $1.52 \pm 0.03 \mathrm{~cm}$ and $1.55 \pm 0.03 \mathrm{~cm}$ for the right and left kidneys respectively (Fig. 4, 5) and (Table 2, 3).

In sagittal planes, the appearance of the structures was depending upon the level of the scanned section. When scanning from medial to lateral, the bright central echo representing the renal sinus disappeared and a central hypoechoic region bordered by two parallel linear echogenecities appeared, the central hypoehoic region represent the renal crest (renal papilla), whereas the linear echogenecities were the dorsal and ventral set of pelvic diverticulae (recesses) accompanied by interlobar vessels (Fig. 6).

The diverticulae and vessels could be recognized as short evenly spaced linear echogenic structure transversing the medullary region toward the cortex (Fig. 4).

The hypoechoic medulla is separated into multiple sections by the diverticulae and interlobar vessels, the diverticulae and vessels are cut transversely in this plane, and the arcuate and interlobar arteries are sometimes recognized as discrete echogenecities at the corticomedullary junction and with the cortex (Fig. 5).

In the transverse plane the medullary region appeared separated into sections by the diverticula and vessels. The solitary renal crest, flanked by the two sets of diverticula, was easily identified. Urine wasn't identified within the pelvis or diverticula nor was the ureter visible in normal animals (Fig. 7).

The renal hilus was visualized in the transverse image of the kidney. The renal vein, artery and ureter were be occasionally visualized in the region of the renal hilus. The following measurements were taken for the right kidney and left kidneys respectively, the depth was 2.74 $\pm 0.09,2.76 \pm 0.09$, diameter of the renal sinus $1.27 \pm 0.06,1.26 \pm 0.06$, diameter renal parenchyma was $1.25 \pm 0.05,1.28 \pm 0.05$ and the circumference of the medullary pyramids was $1.72 \pm 0.09,1.73 \pm 0.10$ (Table 2, 3). 

Table (1): Average of ratio between the length of the right and left kidneys and the length of the 2 nd lumber vertebra.

\begin{tabular}{ccccc}
\hline Animal weight (Kg) & $\begin{array}{c}\text { Length of the right } \\
\text { kidney }\end{array}$ & $\begin{array}{c}\text { Length of the left } \\
\text { kidney }\end{array}$ & $\begin{array}{c}\text { Ratio between RK and Ratio between LK and } \\
\text { L2 }\end{array}$ & L2 \\
\hline $27.15+2.14$ & $5.66+0.19$ & $5.68+0.19$ & $2.30+0.02$ & $2.31+0.02$ \\
\hline
\end{tabular}

Table (2): Average of ultrasonographic measurements of the right kidney.

\begin{tabular}{ccccccccc}
\hline $\begin{array}{c}\text { Animal weight } \\
\text { (Kg) }\end{array}$ & Length & Width & Depth & $\begin{array}{c}\text { Diameter of Circumfere } \\
\text { renal } \\
\text { parenchyma }\end{array}$ & $\begin{array}{c}\text { nce of } \\
\text { medullary }\end{array}$ & $\begin{array}{c}\text { Diameter of } \\
\text { renal sinus }\end{array}$ & $\begin{array}{c}\text { Cortical } \\
\text { thickness }\end{array}$ & $\begin{array}{c}\text { Medullary } \\
\text { thickness }\end{array}$ \\
\hline $24.96+1.81$ & $5.32+0.12$ & $2.79+0.07$ & $2.74+0.09$ & $1.25+0.05$ & $1.72+0.09$ & $1.27+0.06$ & $0.64+0.01$ & $1.52+0.03$ \\
\hline
\end{tabular}

Table (3): Average of ultrasonographic measurments of the left kidney.

\begin{tabular}{ccccccccc}
\hline $\begin{array}{c}\text { Animal } \\
\text { weight (Kg) }\end{array}$ & Length & Width & Depth & $\begin{array}{c}\text { Diameter of Circumfere } \\
\text { renal } \\
\text { parenchyma }\end{array}$ & $\begin{array}{c}\text { nce of } \\
\text { medullary }\end{array}$ & $\begin{array}{c}\text { Diameter of } \\
\text { renal sinus }\end{array}$ & $\begin{array}{c}\text { Cortical } \\
\text { thickness }\end{array}$ & $\begin{array}{c}\text { Medullary } \\
\text { thickness }\end{array}$ \\
\hline $24.96+1.81$ & $5.34+0.12$ & $2.80+0.070$ & $2.76+0.09$ & $1.28+0.05$ & $1.73+0.10$ & $1.26+0.06$ & $0.65+0.01$ & $1.55+0.03$ \\
\hline
\end{tabular}

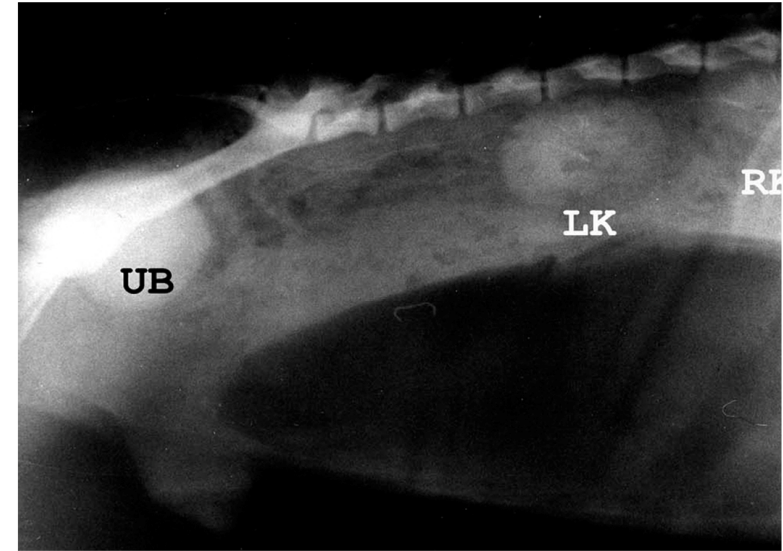

Fig. 1

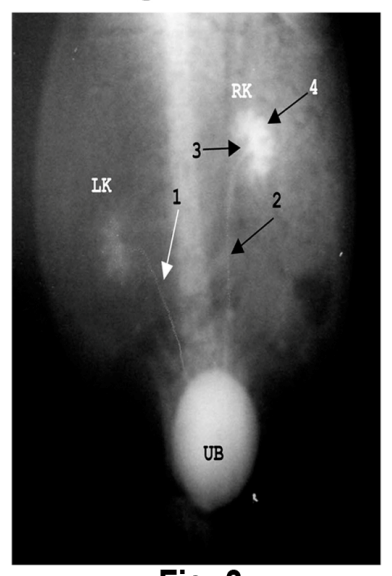

Fig. 3

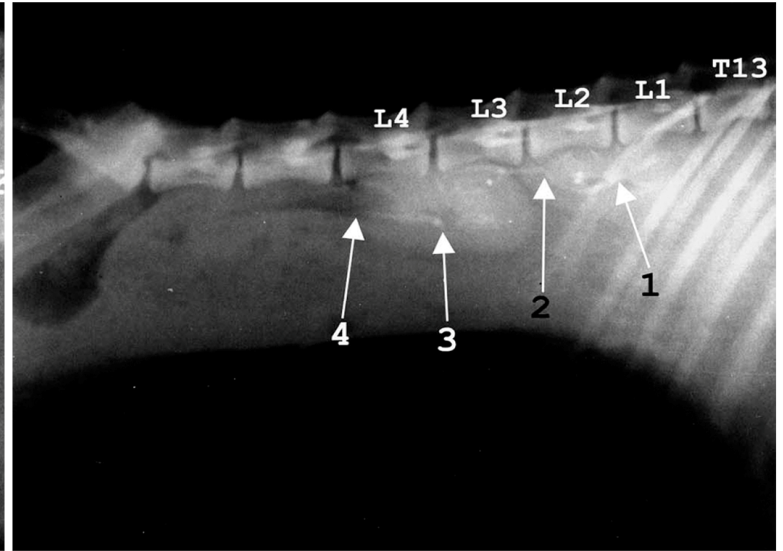

Fig. 2

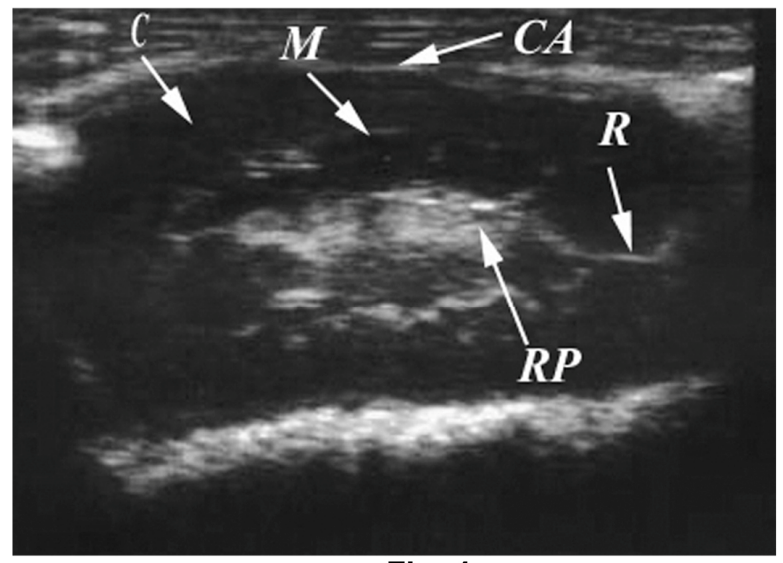

Fig. 4

Fig. (1): Lateral urograph showing the nephrogram phase. RK (right kidney), LK (left kidney), and UB (urinary bladder).

Fig. (2): Lateral urograph showing the pyelogram phase. 1 (origin of the right ureter), 2 (right ureter), 3 (origin of the left ureter), 4 (left ureter), T13 (thirteenth thoracic vertebra), L1 (first lumber vertebra), L2 (second lumber vertebra), $L 3$ (third lumber vertebra), and $L 4$ (fourth lumber vertebra).

Fig. (3): Ventrodorsal urograph showing the pyelogram and the cystogram phases. RK (right kidney), LK (left kidney), UB (urinary bladder), 1 (left ureter), 2 (right ureter), 3 (renal pelvis), and 4 (pelvic recesses).

Fig. (4): Coronal (longitudinal, mid-dorsal) section through the kidney. C (cortex), M (Medulla), CA (renal capsule), $R P$ (renal pelvis and peri-renal fat), and $R$ (recesses). Using 6.0/8.0 MHz linear array transducer. 


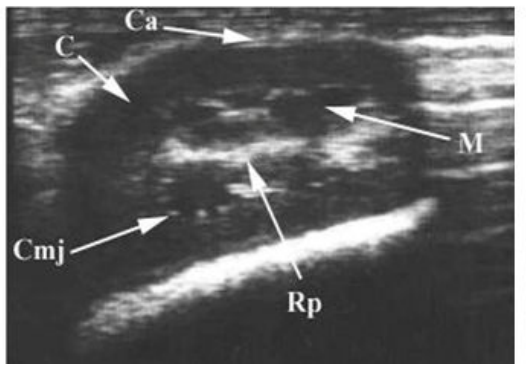

Fig. (5)

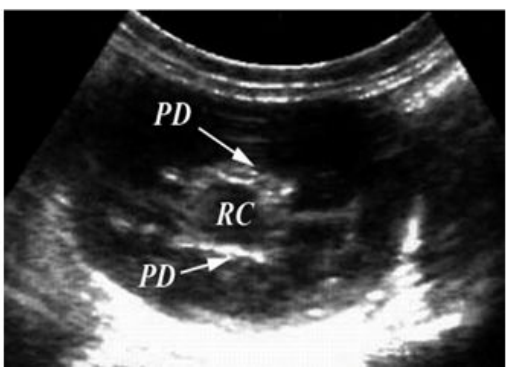

Fig. (6)

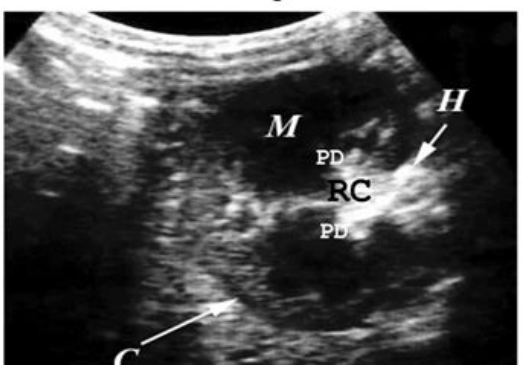

Fig. (7)

Fig. (5): Coronal section through the kidney. C (cortex), M (Medulla), Ca (renal capsule), RP (renal pelvis), and $\mathrm{Cmj}$ (cortico-medullary junction). Using 6.0/8.0 MHz linear array transducer.

Fig. (6): Sagittal plane through the kidney. PD (pelvic diverticulum) and RC (renal crest). Using 3.5/5.0 curved array transducer.

Fig. (7): Transverse plane through the kidney. C (cortex), M (Medulla), H (hilus), PD (pelvic diverticulum), and RC (renal crest). Using 3.5/5.0 curved array transducer.

\section{Discussion}

The achievement of optimal radiographic image in the normal goats required preparation of the animal by fasting for emptying of the GIT and giving diazepam in order to sedate the animal prior to exposure and limit the unnecessary movements. To minimize the fasting period described by Abd El Hamid (1976) from 72 to $48 \mathrm{~h}$ the animals were given rectal enema. And to minimize the residual bowel gas animals were given charcoal tablets. The ultrasonographic examination of the animals required only $12 \mathrm{~h}$ fasting because the animals were examined on standing position as gas filled bowel in this position wouldn't mask the kidneys. This was agreed by (Braun, et al. 1992).

The quality of the radiographic picture was enhanced through using of compression device that was applied to compress the urinary bladder against the spine to occlude the terminal ureters causing stasis and accumulation of the opacified urine in the renal pelvis and the proximal ureters. This in agreement with Abd El Hamid (1976) in sheep and goat, Carlson and Gillette (1967), Mogha, et al. (1972) and Bartels (1972) in dogs and cats, Kralj, et al. (1963) in sheep.

It was found the use of compression device may cause artifacts such as tortuosity, dilatation and distention of the obstructed ureters and distortion of the renal pelvis (Lord et al., 1974; Owens, 1982; Ticer, 1984). This was overcome by taking radiographs immediately after the end of infusion of contrast material before application of the compression band and directly after removal of the compression device. Also compression of the caudal abdomen produces a transient rise in renal blood flow and decreases the glomerular filtration rate within $15 \mathrm{~min}$. Therefore in spite of the fact that ureteral compression causes stasis and dilatation of the diverticulae, the renal pelvis and the proximal ureter, prolonged ureteral compression appears to be counterproductive (Olin and Rees, 1973). In our study the compression device is applied only for $10 \mathrm{~min}$.

The use of high volume prolonged or drip infusion technique with abdominal compression for urography proved to produce good visualization of the urinary system. It has the advantage of requiring fewer radiographs than the other procedures, allowing simultaneous visualization of the kidneys, ureter and urinary bladder. This procedure is normally less time consuming than any of the rapid infusion techniques employing both lateral and ventrodorsal projections since only six radiographs are required to complete the study and very little time is required to apply the compression bandage. This was agreed by (Borthwick and Robbie, 1969; Walker and Douglas, 1970; Suter, 1971). The result showed that ultrasonographic scanning both the right and left kidneys was the right flank region. Diagnostic information potentially gained from survey radiographs and excretory urograms should not be overlooked, as it is often complimentary to the ultrasound findings. The clarity with which the kidneys are seen on plain radiographs depends upon the amount of the peri renal fat present and on the absence of food materials within the GIT (Kealy, 1987). The kidneys were not visualized neither in the ventro-dorsal view nor the lateral view this may be attributed to masking of these organs by the contents of the GIT. This was agreed by Cegarra and Lewis (1977) and disagreed by Abuzaid (1995) and Kealy (1987) where they noticed the shadow of the kidneys in the lateral plain radiographs. 
The visualization of the kidneys during excretory urography depended upon the concentration of the contrast agent within the kidneys and the thickness of the renal tissue through which Roentgen beam passed. The concentration of the contrast agent depended on the plasma level, the glomerular filtration rate and the amount of water absorbed from the glomerular filtration rate in its passage along the nephron (Fry and Cattel, 1972 and Kealy, 1987).

To obtain the best visualization of the kidneys (nephrogram phase), radiographs were made immediately after the contrast agent was injected and still evident till 40 minutes. At this stage the kidneys were opacified by the presence of the contrast agent in the renal capillaries. Similar results were obtained by Abd El Hamid (1976); Singh, et al. (1983); Kene (1986) and Abuzaid (1995).

The position of the right kidney was more constant due to its close relationship with the liver (hepatorenal ligament and renal fossa). Whereas the position of the left kidney usually changed and may attributed to the animal position and the volume of the ruminal contents. This was due to its loose attachment by long mesentry thus it was affected by the surrounding organs specially the full rumen that might displace it to the right side. This was agreed by Abd El Hamid (1976); Cegarra and Lewis (1977); Singh, et al. (1983); Kene (1986) and Abuzaid, (1995) or to the compression applied on the abdominal wall (Kralj, et al. 1963).

The renal pelvis and recesses were demonstrated in the radiographs taken at the end of infusion of the contrast solution but it was best visualized after 10 minutes from the end of infusion and remain evident till 30 minutes post injection of the contrast agent. The pelvic recesses were about 10-12 radiating streaks indented by papillae, this was agreed with the findings of Singh, et al. (1983) and Cegarra and Lewis (1977).

Ultrasonographic examination of the kidneys provided additional information about size, shape and internal architecture and identifies kidneys not seen on survey radiographs or excretory urogram because of decreased abdominal contrast or poor function. Also renosonography allows examination of the kidneys through multiple scanning planes (Walter, Feeny, Johnston and O'Brien, 1987).

As reported by Konde et al., (1984); Wood and McCarthy (1990) and Nyland and Mattoon (1995) in the dog Walter et al., (1987) in cat;
Yamaga and Too (1984); Braun et al., (1992) and Hafez and El Khodery (2001) in sheep Abu Zaid (1995) in goat and in the present study, the renal cortex appeared more echogenic than the medulla. Such difference in echogenicity is related to the histological structure of these organs. Histologically the cortex contains larger number of glomeruli with hypercellularity and larger portions of the Hennele's loop provide the collagen tissue interface, while the medulla has only thin walled collecting tubules with the excreted urine. In other words the medulla has more water content and intern relatively fewer acoustic interface than the cortex.

In the sagittal plane a central hypoechoic region (renal crest) borded by two parallel linear echogenecities(dorsal and ventral sets of pelvic diverticula) appeared. Similar observations were recorded by Nyland and Mattoon (1995) in dog and cat.

The renal medulla was separated into multiple sections by the diverticula and interlobar vessels which were cut transversely and recognized as a discrete echogenicity at the corticomedullary junction. Similar results were recorded by Nyland and Mattoon (1995) in dog and cat.

In the transverse plane the medullary region appeared separated into sections by the diverticula and vessels. The solitary renal crest, flanked by the two sets of diverticula, was easily identified. Urine wasn't identified within the pelvis or diverticula nor was the ureter visible in normal animals. These observations were recorded by Nyland and Mattoon (1995) in dog and cat

The renal hilus could be always visualized in the transverse image of the kidney. The renal vein, artery and ureter could be occasionally visualized in the region of the renal hilus; however, they could not be differentiated from each other. These observations were recorded by Konde et al., (1984); Wood and McCarthy (1990) and Nyland and Mattoon (1995) in dog, Walter et al., (1987) in cat; Yamaga and Too (1984); Braun et al., (1992) and Hafez and El Khodery (2001) in sheep Abu Zaid (1995) in goat.

The dimensions of the kidney are essential for assessment of the status of the kidney whether it is normal or abnormal. On the urographic image the length of the kidneys ranged between $4.5-6.5 \mathrm{~cm}$. This was nearly the same as that recorded by Nickel et al., (1979) where the kidney's length was $5.5-7.0 \mathrm{~cm}$. At 
this wide range it was considered that the relationship between the right and left kidney to the second lumber vertebra was more accurate estimation of the kidney size. The kidneys were 2.1 to 2.6 times the length of the second lumber vertebra. This ratio was recorded by (Cegarra and Lewis, 1977 and Abuzaid, 1995).

The radiographic measurement of the kidneys is often inaccurate because of a combination of geometric distortion and magnification. Urography can overcome some of the problems associated with plain films assessment but also can add to the dilemma by increasing kidney size secondary to osmotic diuresis.this was agreed by (Charles, 2003).

\section{References}

Abd El Hamid, M. A. (1976): Intravenous pyelography in sheep and goat. MVSc thesis, Fac. Vet. Med., Cairo Univ, Giza, Egypt.

Abuzaid, R. M. (1995): Radio and sonographic anatomical studies on the goat. MVSc thesis, Fac. Vet. Med., Suez Canal Univ.Suez Canal, Egypt.

Bartels, J. E. (1972): Feline intravenous urography technique. Modern Vet. Pract. 55: 868-869.

Biery, D. N. (1978): Upper urinary tract: In O'Brien, T. R. radiographic diagnosis of abdominal disorders of dogs and cats. WB Saunders, Philadelphia.

Borthwick, R. and Robbie, B. (1969): urography in the dog by an intravenous infusion technique. J. Small Anim. Pract., 10:465.

Braun, U.; Schefer, U. and Gerber, D. (1992): Ultrasonography of the urinary tract of the female sheep. Am. J. Vet. Res., 53 (10) : 1734-1739.

Carlson, W. D. and Gillette, E. L. (1967): Vetrinary radiology. $2^{\text {nd }}$ Ed. Lea Febiger; Philadelphia

Cegarra, I. J. and Lewis, R. E. (1977): Excretory urography in the goat (capra hircus). Am. J. Vet. Res., 38: 1129-1132.

Charles, S.F. (2003): Veterinary diagnostic imaging of the dog and cat. Vol 1, Saskatoon, Saskatchewen, Canada.

Dyce, K. M.; Sack, W. O. and Wensenig, C. J. (1987): Text book of veterinary anatomy. Ch. (5) Pp. $162-204$. WB Saunders, Philadelphia.

Fry, I. K. and Cattel, W. R. (1972): The nephrogenic pattern during excretion urography. Br. Med. Bull. 28: 227231

Hafez, A. N. and El Khodery, S. A. (2001): Ultrasonography of healthy and diseased sheep. Elmasoura Magazine, 3: 445-458.

Kealy, J. K. (1987): Diagnostic radiology of the dog and cat. Chapter 2, Pp. 112-170, $2^{\text {nd }}$ ed, Wb Saunders Co., Philadelphia, London.

Kene, R. O. C. (1986): Double contrast radiographic study of normal caprine urinary tract. Trop. Vet., 4: 121-126.
Konde, L. J.; Wringley, R. H.; Park, R. D. and Lebel, J. L. (1984): Ultrasonographic anatomy of the canine kidney. Vet Rad., 25: 173-178.

Kralj, J. Jansek, E. and Milosevic, Z. (1963): Intravenous pyelography in sheep. Mh. Vet. Med., 18:254-258.

Lord, P. F.; Scott, R. C. and Chan K. F. (1974): Intravenous urography for evaluation of the renal diseases in small animals. J. Amer. Anim. Hosp. Assoc., 10:139.

Mogha, I. V. Angelo, S. J. and Das, S. C. (1972): Observation on experimental pyelography in canines. Ind. Vet. J., 49: 305-313.

Morgan, J. P. and Silverman, S. (1982 ): Techniques of veterinary radiology. $3^{\text {rd }}$ ed, Davis. CA,veterinary radiology associates.

Nickel, R.;Schummer, A.; Seiferle, E. and Sack, W. O. (1973): The viscera of the domestic mammals. Vol. I -283 : 324 Verlg Pareg Berlin Hamburg

Nyland, T. G. and Mattoon, J. S. (1995): Veterinary diagnostic ultrasound. Chapter 8, Pp. 95-124, Wb Saunders Co., Philadelphia, London

Olin, T. R. and Rees, D. O. (1973): Renal function at urography with compression- An experimental investigation in rabbit. Acta. Radiol. 14 pp. 613.

Owens, J. M. (1982): Radiographic interpretation for the small animal clinician. St. Louis, MO, Raliston Purina Co.

Scott P. R., Sargison N. D. and Wilson D. (2001): Ultrasonographic findings of urinary retention caused by a vaginal stricture following dystocia in a ewe. Vet. Rec., 10:315-3156.

Singh, A. P.; Singh, J.; Williamson, H. D.; Peshin, P. K. and Nigam, J.M. (1983): Radiographic visualization of the upper urinary tract by a double contrast technique. Vet. Radiol., 24:106-111.

Sisson, S. S. and Grossman, J. D. (1975): The anatomy of the domestic animals. $4^{\text {th }}$ Ed. 564-620 W.B. Saunders Co. Philadelphia London

Suter, P. F. (1971): Adverse reactions during urography and modification by atropine. Acta. Radiol., 11: 427.

Ticer, J. w. (1984): Radiographic technique in veterinary practice $2^{\text {nd }}$ ed, W.B. Saunders Company Philadelphia, London, Torinto.

Walker, R. G. and Douglas, S. W. (1970): The use of contrast media in the diagnosis of urinary tract abnormalities in the dog with particular reference to infusion urography: a report of two cases. Vet. Rec., 87:287 Walter, P. A.; Johnston, G. R.; Feeny, D. A. and O'Brien, T. D. (1987): Renal ultrasonography in healthy cats. Am. J. Vet. Res., 48: 600-607.

Watters, J. W. (1980): Urinary tract radiology-Kidneys and ureters. Comp. Cont. Ed. 2: 224.

Wood, W. K. A. and McCarthy, P. H. (1990): Ultrasonographic- anatomic correlation and imaging protocol of the normal canine kidney. Am. J. Vet. Res., 51: 1: 103-108.

Yamaga, Y. and Too, K. (1984): Diagnostic ultrasound imaging in domestic animals. Fundamental studies on abdominal organs and fetuses. Jpn. J. Vet. Sci., 46:2: 203212 . 


\section{دراسات راديولوجية وموجات فوق صوتية على الكلى فى الماعز}

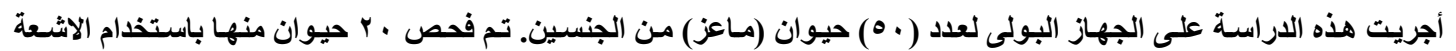

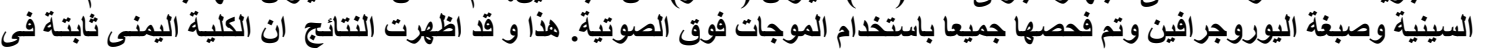

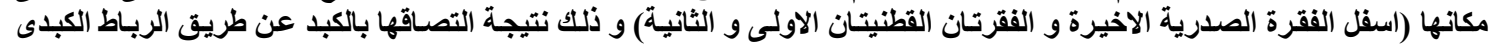

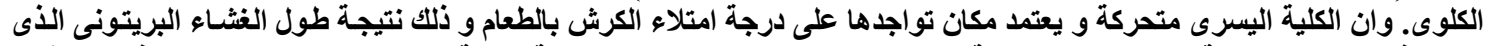

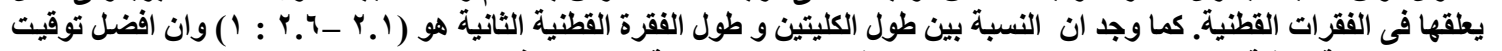

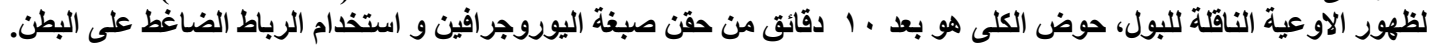

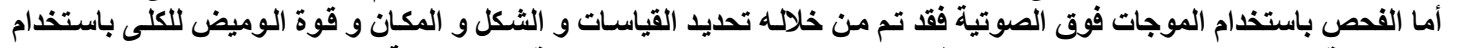

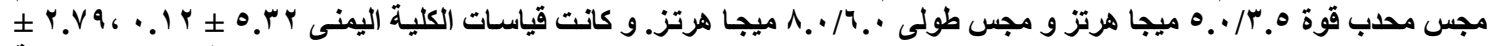

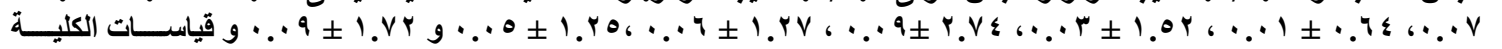
اليســـ צ צ

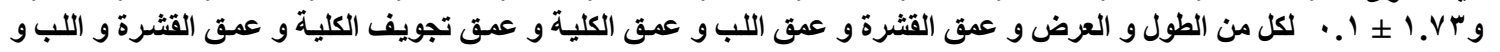
محيط اللب الهرمى على التوالى. 